Original Research Paper

\title{
Determination of Natural Frequencies through Modal and Harmonic Analysis of Space Frame Race Car Chassis Based on ANSYS
}

\author{
Mohammad Al Bukhari Marzuki, Mohammad Hadi Abd Halim and Abdul Razak Naina Mohamed \\ Department of Mechanical Engineering, Sultan Azlan Shah Polytechnic, Behrang, Perak, Malaysia
}

Article history
Received: 27-10-2014
Revised: 10-02-2015
Accepted: 11-07-2015
Corresponding Author:
Mohammad Al Bukhari
Marzuki
Department of Mechanical
Engineering, Sultan Azlan Shah
Polytechnic, Behrang, Perak,
Malaysia
Email: menaven2@yahoo.co.uk

\section{Introduction}

Nowadays, there are various formula-style racing competitions for universities students around the world to compete. Among the notable student-based competition are the Formula SAE (FSAE) and Formula Student. Normally, the formula-style design and race based competition require the participant to design, fabricate and finally race against each other in a highly competitive tournament. The competition imposes some limitations on the chassis design and engine capability requires the student to use their knowledge and creativity to overcome the limitation. Space frame is one of the compulsory requirements in designing the chassis. The use of space frame provides notable advantages is the mass of the chassis structure is lower and cost effective compared with

\begin{abstract}
Space frame chassis the preferred choice of chassis design due to its low cost, high strength, lightweight and safe qualities, which it suitable for a single-seat race car application and an important hoops, side impact protection and crush zone sub-frame. These sections are pivotal in the safety aspect of the driver during emergency situation. investigate the mode shape and natural frequencies in the structure. Two methods are mainly used in the study, modal analysis and harmonic analysis with both analyses are performed using Finite Element (FE) method through Finite Element Analysis (FEA) software packaged, ANSYS v13 APDL Mechanical. The study identified five mode shapes is further explained in this study. Amplitude vs. frequency graph is generated from harmonic analysis is utilised to determine the resonance frequency. The highest amplitude occurred in the third natural frequency with an amplitude of $0.375 \mathrm{~mm}$. The outcome of this analysis can be used as a reference in improving the chassis design and performance against dynamic behaviour of the structure by introducing
\end{abstract}

Keywords: Modal, Harmonic, Space Frame, ANSYS, Natural Frequency other type of chassis, however complicated manufacturing process, limits its usage only to performance and niche market cars. The construction of the chassis structure is divided into several sections namely, Main Hoop, Front Hoop, Side Impact Protection and the Crush Zone. The functions of the main sections in the chassis structure is vital for the safety of the driver, in which, both Main Hoop and Front Hoop will protect the driver in case of rollover and to ensure upper part of the driver's body is sufficiently covered. The Side Impact Protection subframe is constructed to protect the driver from any collision on the either side of the car. As part of the main chassis structure, the Crush Zone is located on the front section of the chassis. It is specifically designed to absorb energy during head on collision. The main section of the chassis is shown in Fig. 1. 


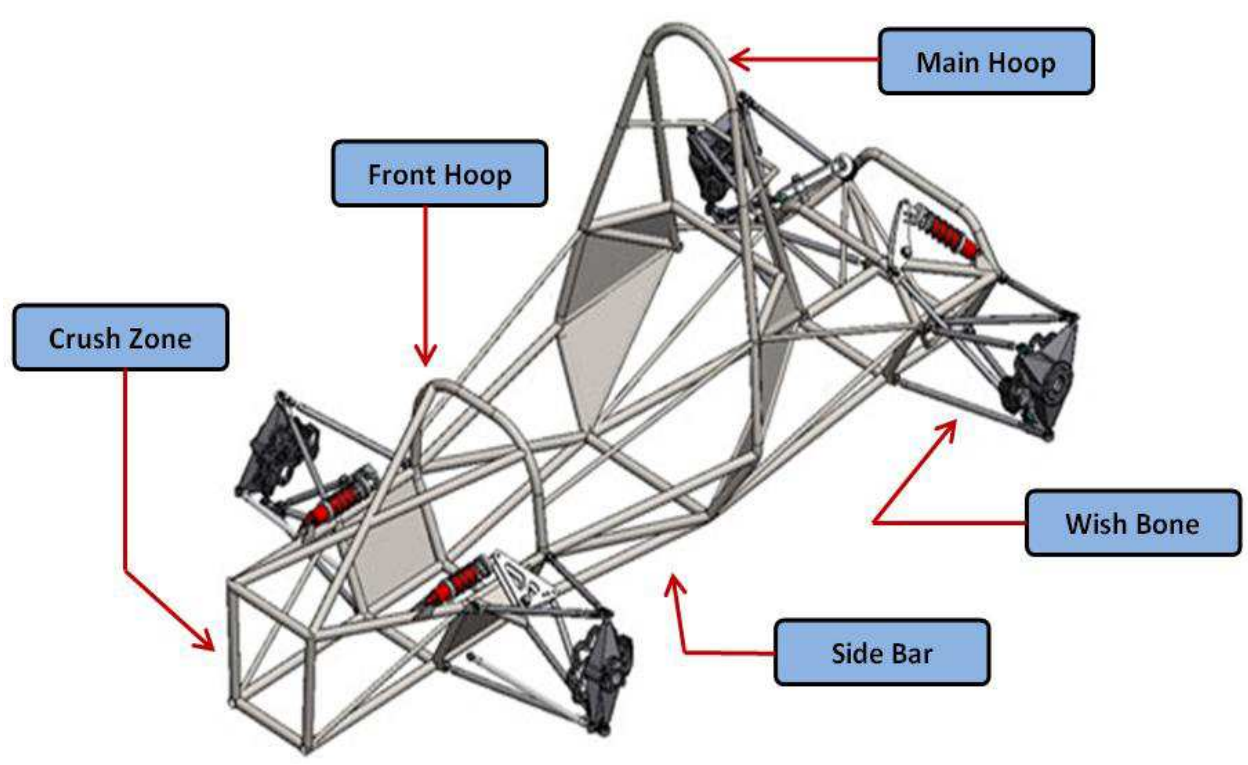

Fig. 1. An example of space frame chassis structure

Different chassis structure produces different dynamic characteristic, therefore it is important to study dynamic characteristic to ensure the structure and vibration failures do not occur during the chassis operating life. There are various ways to analyse dynamic characteristic of a structure, among the well-known method of extracting dynamic behaviour in a structure is Modal Analysis and Harmonic Analysis, from which natural frequencies, mode shape and resonance frequency of a structure can be ascertained. Vehicle chassis structure usually dynamically excited from uneven or rough road profile, engine and transmission vibration and etc. Under the dynamic excitation experienced by the chassis, the chassis structure will vibrates. If the vibration caused from the external excitation is the same as the natural frequency it will cause a phenomenon called resonance, which can lead to excessive deflection and failure as explained by Rao (2004). First natural frequency or resonance is one of the contributing factors for vibration and noise related problems that occur in structures and machineries. The dynamic characteristic can be analysed through experimentation and simulation. With advancement in hardware computing power finite element analysis simulation has made possible and gained it place in complement with experiment based analyses.

There are several software that can be used to analyse dynamic behaviour, computer-based finite element analyses ANSYS, dynamic characteristic can be obtained using variety of vibration and structural design analyses packaged in the software as described by (Lin et al., 2012; Wang and Sun, 2010). Earlier study by Suhir and Burke (1994) concurred that, finite element analysis using finite element method is a practical tool to identify structural dynamic behaviour such as mode shape and natural frequencies. As explained previously by Rao (2004), forced external excitation from engine's imbalance cycle and uneven road condition could lead to failure. Further studies conducted by Ferreira and Lopez-Pita (2012) and analysed by (Gou-Lin and Dai-Sheng, 2008; Yang et al., 2012) in which they conclude that if excitation signal frequency and the response frequency of the skin structure is similar, the mechanical structure will produce resonance and deflection. Naveen and Venkatesh (2014) presented from the mode shape generated from two wheeler chassis derived from Operation Deflection Shape (ODS) analysis produced six experimental mode shape, includes torsion, lateral bending and vertical bending in different modes. Computational method is a modern technique to find mode shapes of a structure where the rigidity of the structure can be analysed and the resonance vibration could be avoided. Madhu and Venugopal (2014) study shows that 14 mode shapes is extracted from the modal analysis and actual vibration characteristic under varied frequency range can be predicted. The result from Madhu and Venugopal (2014) can be used a reference value for other analysis related to dynamic behaviour i.e., random analysis, harmonic analysis based on similar structure configuration of the study.

A harmonic analysis is used to calculate the response of the chassis structure to a cyclic load over a frequency range and the result is plotted on amplitude vs. frequency graph to provide valuable dynamic characteristic information concerning the chassis structure. ANSYS's Harmonic Analysis module can simulate a structural response under forced vibration from imbalance engine 
cycle drive and the module efficiently extract the forced excitation amplitude deflection of the structure, which later can be used to predict and prevent damage and large deflection to the structure as explained in studies by (Zhang and Kang, 2013; Luo et al., 2012). Ahmad and Brahmananda (2003) presented a result from motorcycle chassis mode shape analysis showed that large displacement at handlebar position could cause the rider discomfort and the first two frequencies obtained lies in the human discomfort region $(0-100 \mathrm{~Hz})$. Thus, further study and modification is needed to bring the motorcycle chassis vibration within the human comfort zone. As stated earlier, vibration analysis can be done experimentally, but the cost of conducting using this method is expensive compared to simulation based analysis. However, the result from the analysis will be more precise compared with the simulation based counterpart. This is due to over simplification of the physical model in the simulation, apart from selecting unsuitable element and coarse element meshing which can lead to producing inaccurate result.

There are several studies related to experimental vibration analysis, for instance in reference to work performed by (He and $\mathrm{Fu}, 2001)$. In this study the chassis is tested experimentally by suspending the chassis structure with springs to simulate free-free boundary condition and the chassis is excited using a shaker so that the mode shape of the chassis can be derived. Another notable study on experimental harmonic analysis on full sized vehicle chassis is performed by Wenlin et al. (2010). The study utilised Land-Wind X6 chassis, data acquisition system and an input hammer, which produced eleven mode shapes with the frequency below $150 \mathrm{~Hz}$ are then verified with Modal Assurance Criteria (MAC) method for validation.

Although there are various of research on car chassis structure vibration analysis both experimentally and simulation, but most of the research are not fully address modal and harmonic analysis specifically on space frame race car chassis. The goal of the study is to analyse the mode shape of the space frame race car chassis structure under vibrational excitation through modal analysis and to determine the steady-state response of linear structure on harmonic analysis using Finite Element (FE) method. This study acts as aninitial step to perform vibration analysis experimentally.

\section{Theory of Vibration Analysis}

Frequency Response Function utilises measurement techniques of Fast Fourier Transform (FFT), which is widely used in analysing structural dynamic especially in automotive industries to establish vibration characteristic i.e., mode shape, natural frequencies of vehicle model (Mahmoodi-k et al., 2014). The equation of motion for undamped system is formulated from:

$$
[m]\{\ddot{q}\}+[k]\{q\}=\{0\}
$$

where, $\mathrm{m}, \mathrm{q}$ and $\mathrm{k}$ is the constant which describe the mass, displacement and stiffness of the system and Equation (1) equal to zero if there is no force applied to the system. $\mathrm{q}$ is displacement for a linear system, which in harmonic form will be Equation 2:

$$
\{q\}=\left\{Q_{i}\right\} \sin \left(\omega_{i} t\right)
$$

where, $Q_{i}$ is the amplitude of mode shape of the $i^{\text {th }}$ natural frequency $\omega_{i}$, therefore:

$$
-\omega^{2}[m]+[k]=\{0\}
$$

The solution from Equation (3) gives Eigen values, which is the square root of the natural frequencies and the Eigen vectors are the amplitude of the corresponding natural frequencies. The natural frequencies gathered from the modal analysis can be used to provide information on critical mounting points for vibration sourced component i.e., engine, transmission, suspension system, electric motors and etc.

\section{Finite Element Model Geometry}

Most of the racecar design regulations are loosely based on the Formula SAE design criteria (Formula SAE ${ }^{\circledR}$ Rules). There are three main sections used in the construction of the space frame chassis, with all the different section are intended for the specific purposes of the chassis structure. A $27 \mathrm{~mm}$ diameter tube with wall thickness of $2 \mathrm{~mm}$ is used for both front and main hoops construction. Other tube frame construction such as the side beam and front beam is constructed by using a $25 \mathrm{~mm}$ with $1.6 \mathrm{~mm}$ wall thickness tube. The wish bone section of the chassis is constructed with $19 \mathrm{~mm}$ tube with $1.2 \mathrm{~mm}$ wall thickness. The thicker tube is selected for both front and main hoops section since it can withstand any rolling impact in case the car rolls over. The wish bone is assumed as not a part of the chassis structure because it is not permanently fixed to the main structure. The entire tube specifications and thicknesses are entered to the section geometry (SECDATA) option in the ANSYS software. The chassis structure modelling is done entirely on ANSYS Mechanical APDL.

The actual race car model is shown in Fig. 2. Chassis structure carries the engine and fuel tank located at rear, single seat passenger and electrical equipment at mid chassis and braking and steering system component is placed at the front section. All equipments and components as well as the passenger are excluded from the analysis to ensure the accuracy in the result. 


\section{Geometry Meshing}

The model in ANSYS is assumed to be made from tube frame in which PIPE288 element is selected tosimulate the car chassis. PIPE288 element is chosen because the element is suitable for analyzing short pipe structures which based on the Timoshenko beam theory with shear deformation effect are included (ANSYS, 2010). PIPE288 is a 3-D linear, quadratic two-noded pipe element which has six degrees of freedom, making the element suited for linear, large rotation and strain nonlinear application (ANSYS, 2010). Key point is created by using the dimension according to the actual chassis construction and then the key points created are connected using lines option and the lines are meshed using mesh tool in ANSYS. The model is meshed using mapped element with equivalent size on every line. A total of 5875 nodes and 5900 elements are created. The total number of nodes and elements created are sufficient to produce an acceptable result, the simplified finite element meshed model is illustrated in Fig. 3-6.

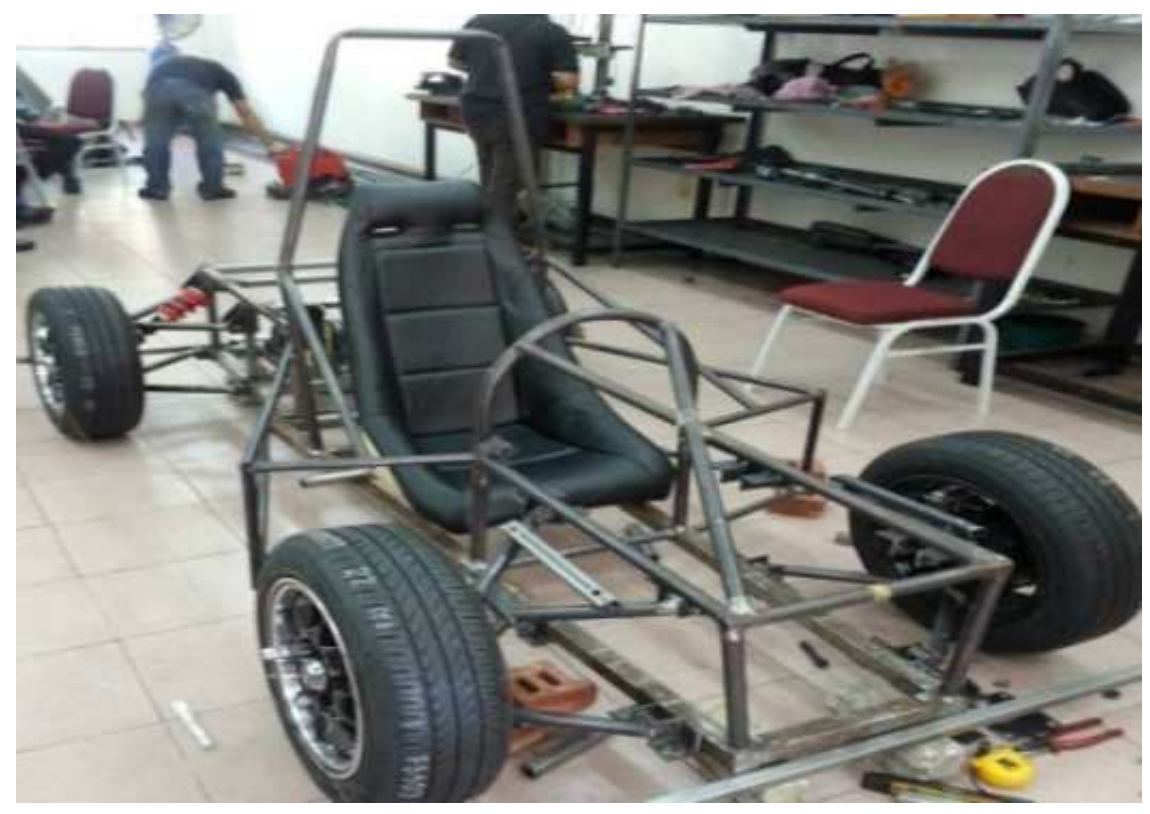

Fig. 2. The actual space frame race car chassis PSAS Motorsport Team

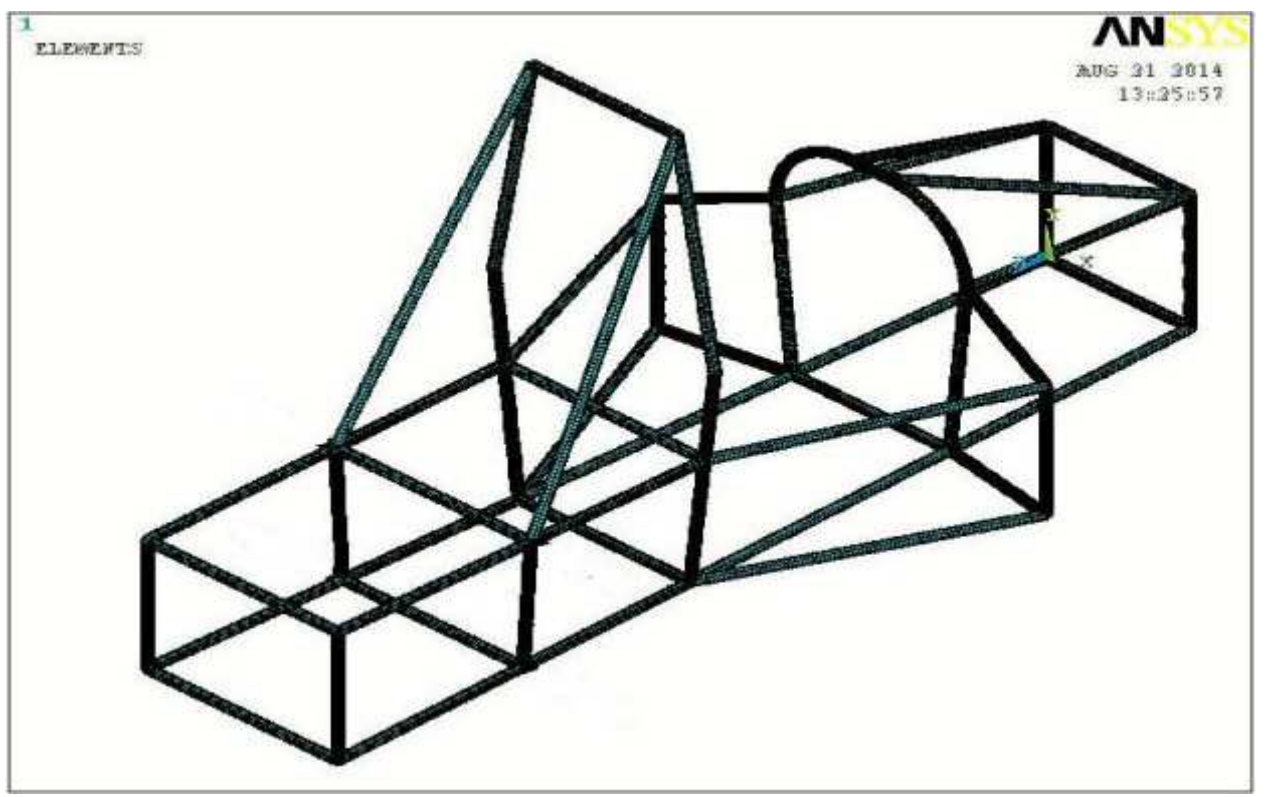

Fig. 3. The simplified model in ANSYS in isometric view 


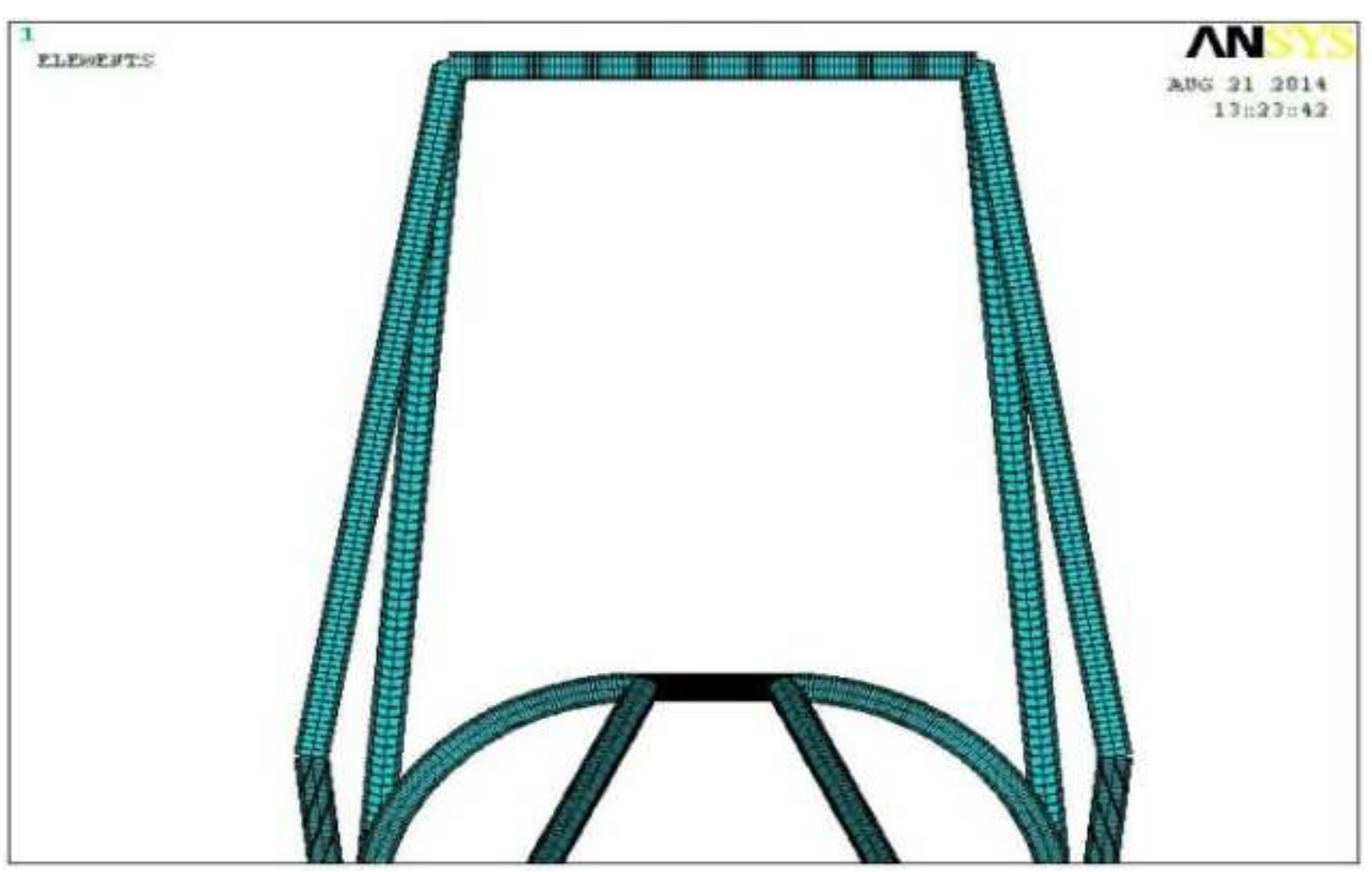

Fig. 4. Front and main hoop

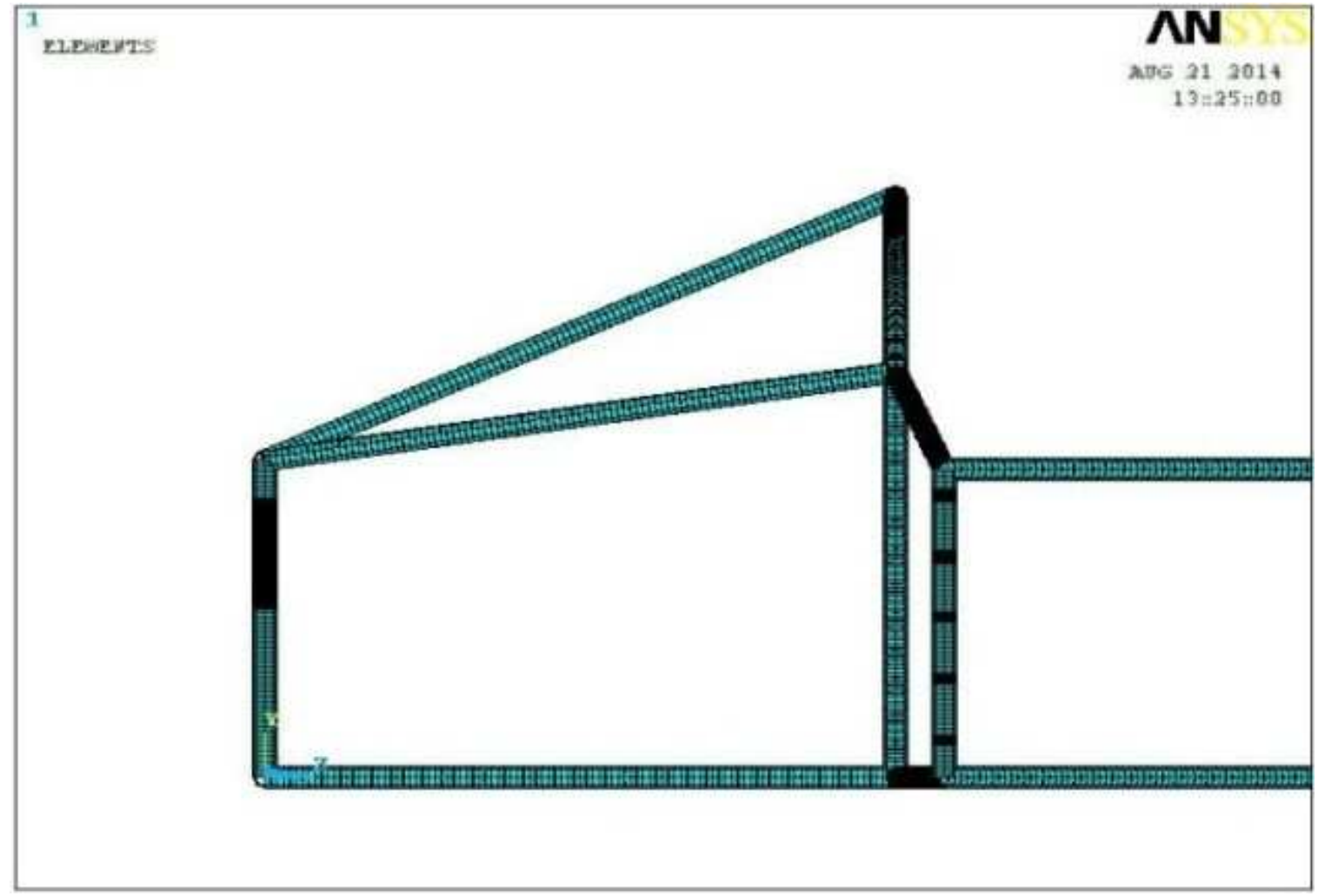

Fig. 5. Front section 


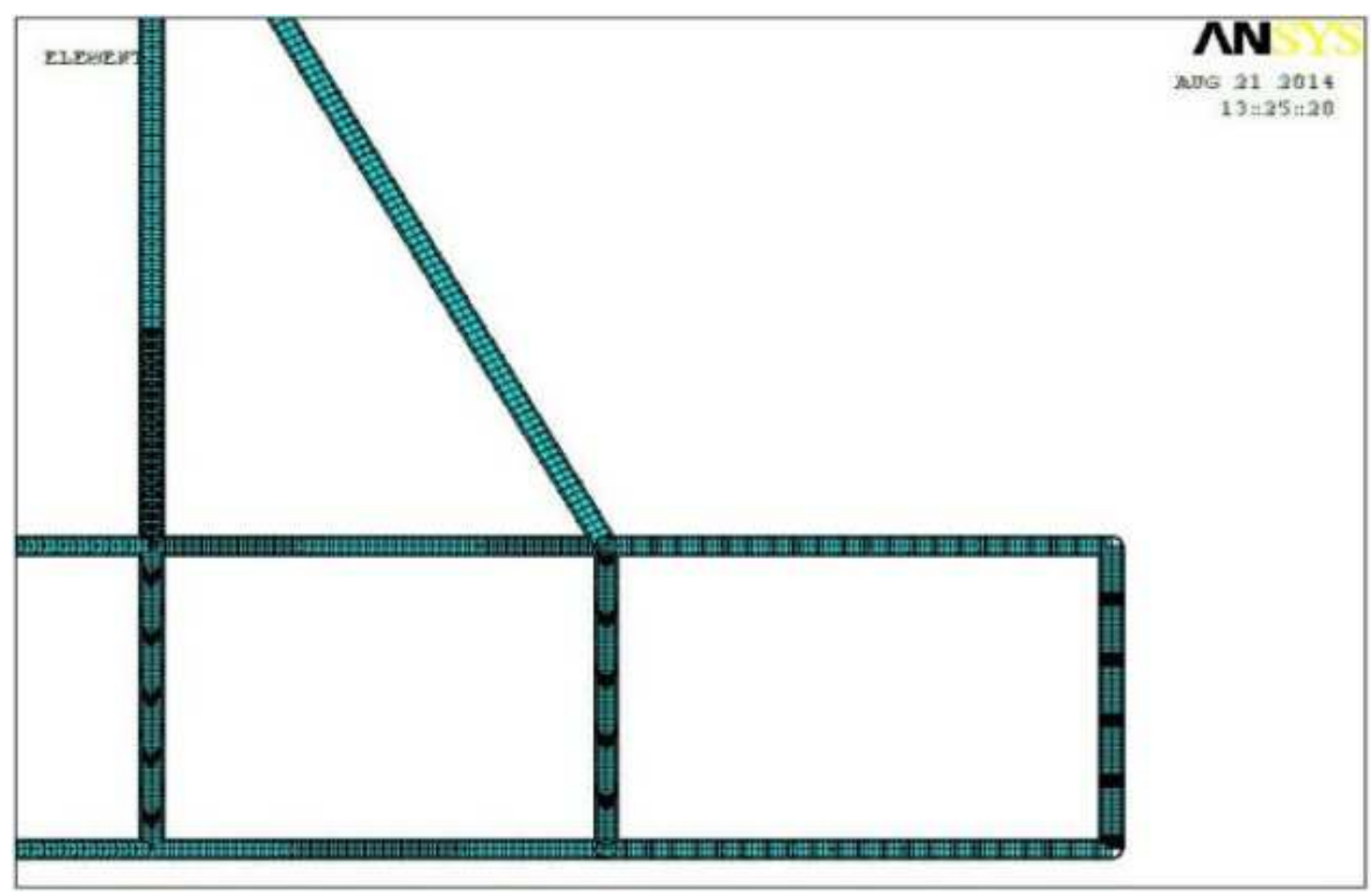

Fig. 6. Rear section

\section{Material Properties}

All of the tube is made from steel. The selection of steels as the material from chassis construction is based on the rules and regulation set by FSAE. In the rules, there are only two type of materials can be used for constructing the car chassis which arealuminium and steels and for the analysis purposes, steels is selected. Steels have a material density of $7860 \mathrm{~kg} / \mathrm{m}^{2}$, a Poisson's Ratio of 0.3, Young's Modulus of $200 \mathrm{GPa}$ and yield strength of $355 \mathrm{MPa}$.

\section{Boundary Condition}

Since no weight is carried by the chassis, therefore there are no loads are applied in vibration analysis with all degree of freedom are free to evaluate the natural response of the chassis structure. For analysis purposes, damping coefficient is ignored for both modal and harmonic analysis.

\section{Finite Element Result}

\section{Modal Analysis}

This study utilise modal analysis to generate the natural frequencies and mode shapes of the space frame chassis structure. Result from Modal Analysis is important as it can predict the response of structural parameters under dynamic loading condition. Mode shapes simulated from Modal Analysis can provide the information of how the chassis structure will naturally displace. ANSYS APDL Mechanical is used as preprocessor, solver and post-processor for the modal analysis. The mode shapes are extracted using Block Lanczos method. Block Lanczos method has been used in studies for extracting mode shapes and natural frequencies (Hai-Fei et al., 2014; Venugopal Rao and Chinta, 2014; Samrudhi et al., 2014). From the result, 5 modal analysis results are obtained between $0-800 \mathrm{~Hz}$ range; Fig. 7 to 11 illustrate the first five natural frequencies for the corresponding mode shape which are important to the study. Mode shapes frequencies and characteristic are tabulated in Table 1 .

Table 1 outlines the first natural frequency for the chassis is at approximately $150.39 \mathrm{~Hz}$. The mode shape of the race car structure is critical because resonance usually occurs in these frequencies. The second modal frequency is vibrated at $203.15 \mathrm{~Hz}$, the third modal frequency vibrated at $389.10 \mathrm{~Hz}$, fourth modal frequency at $515.66 \mathrm{~Hz}$ and the last modal frequency within $0-800 \mathrm{~Hz}$ range vibrated at $759.38 \mathrm{~Hz}$.

The 5 mode shapes are produced by ANSYS illustrates different modal frequency characteristic. The first mode shape generated a bending behavior, occurred at the rear section of the chassis. If the bending behavior is animated in ANSYS, it produced a flapping-like animation resembling a bird flapping its wing, as called by Wenlin et al. (2010). 


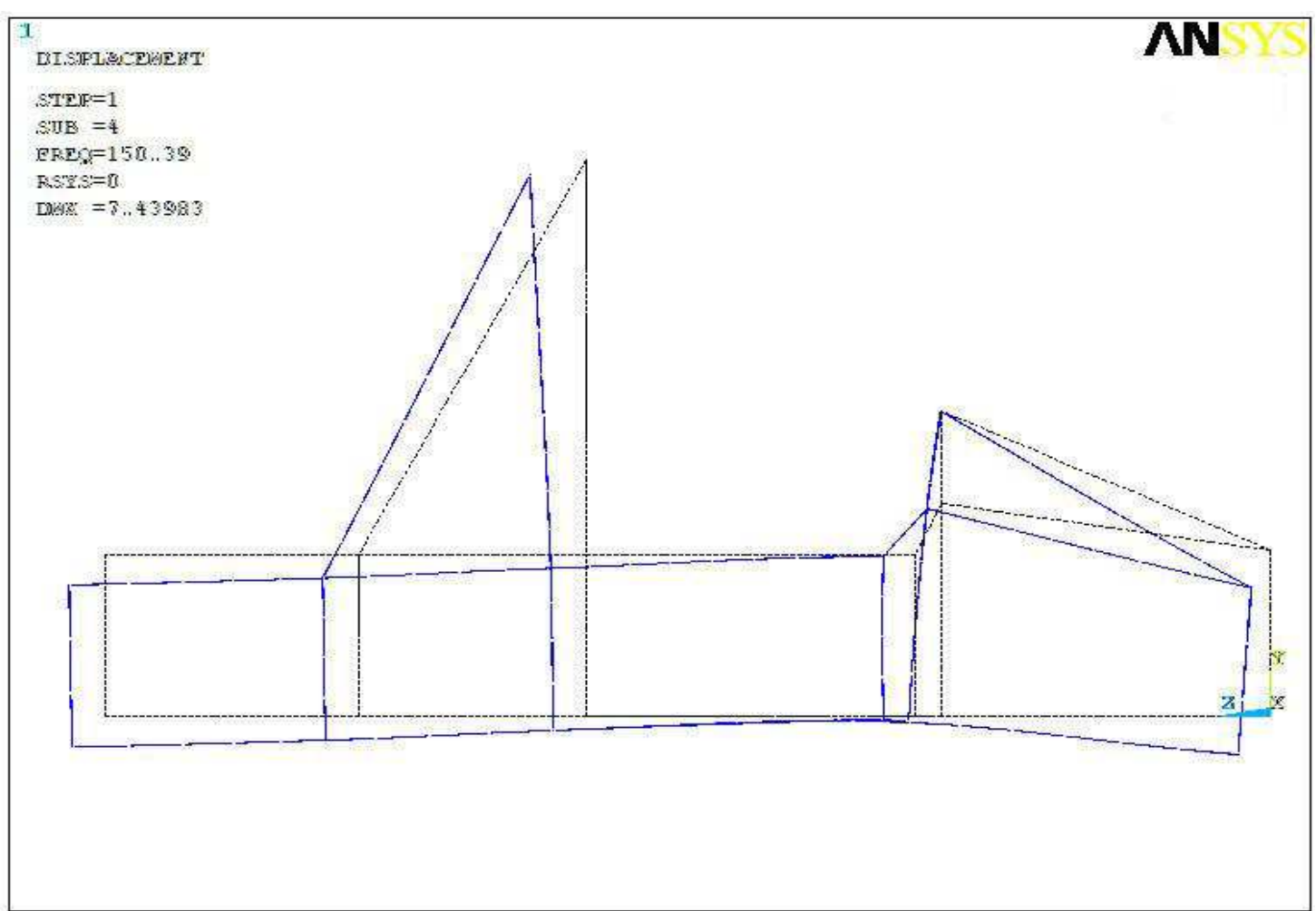

Fig. 7. First mode shape

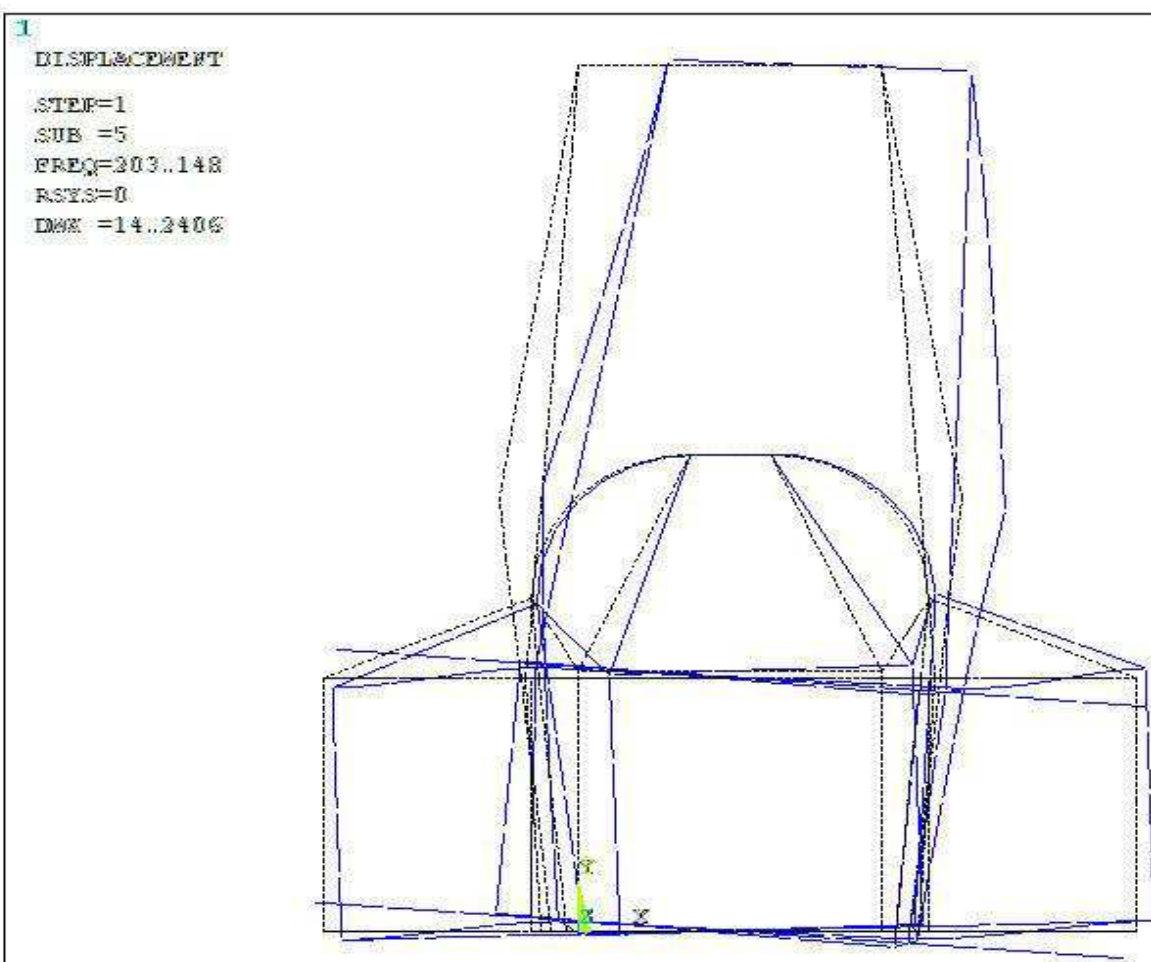

NN

Fig. 8. Second mode shape 


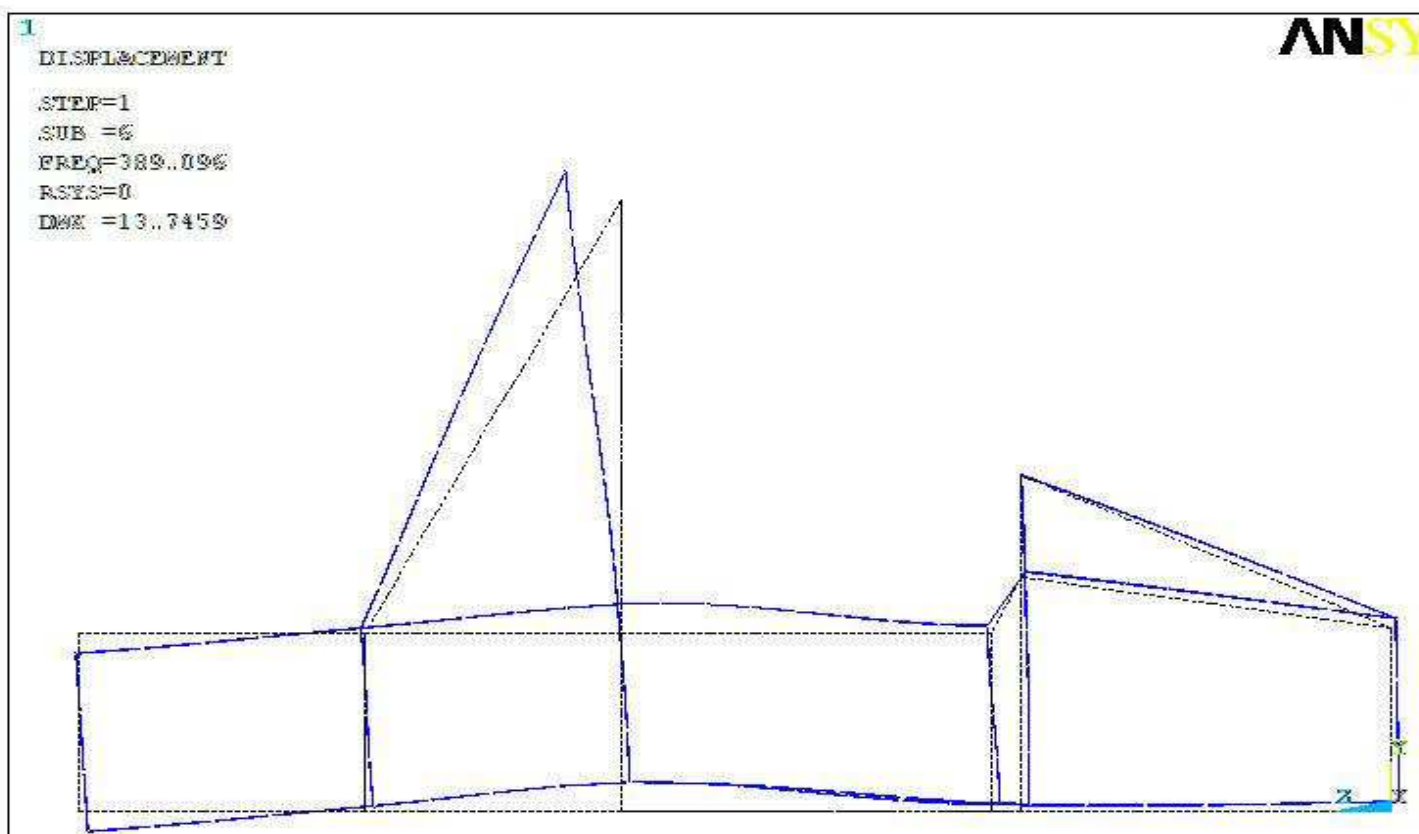

Fig. 9. Third mode shape

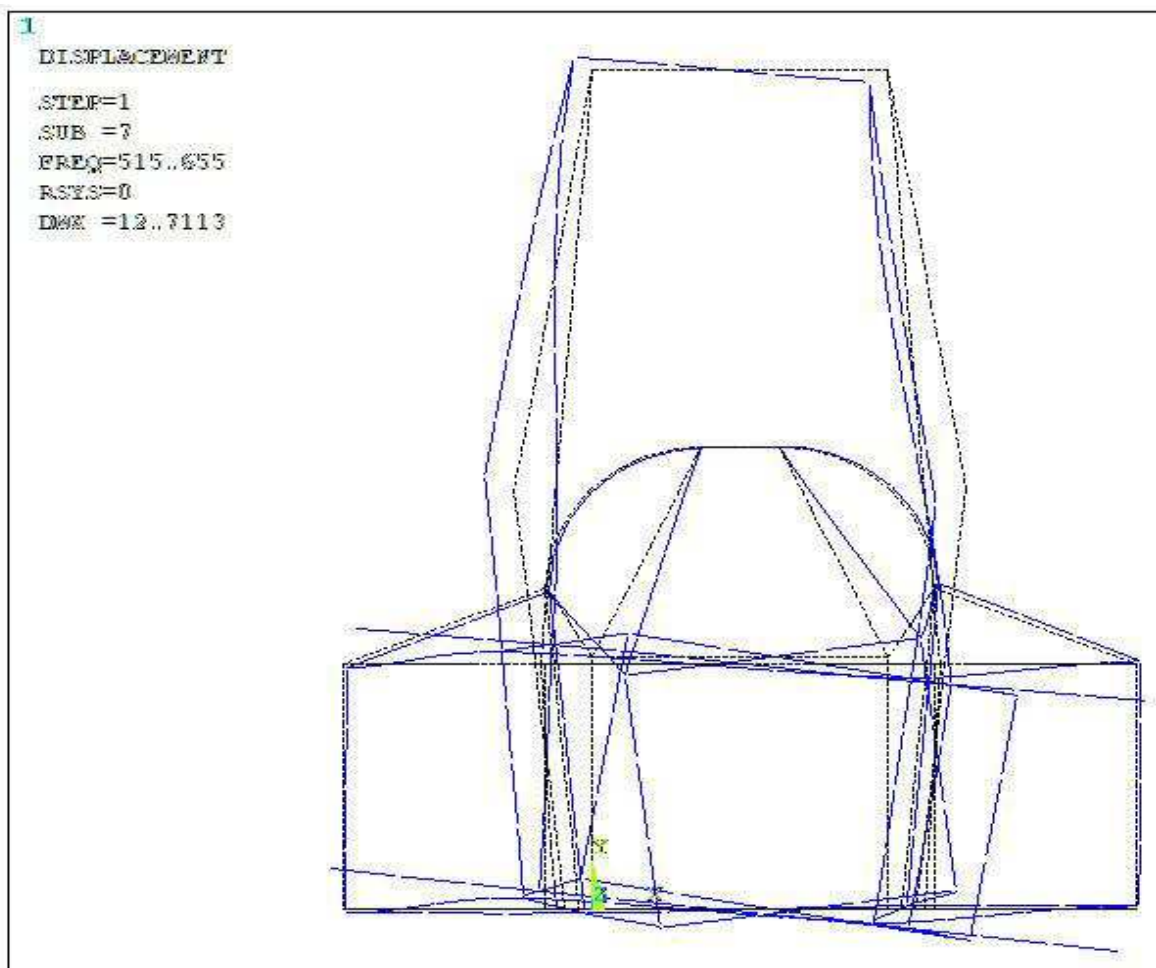

NN

Fig. 10. Fourth mode shape 


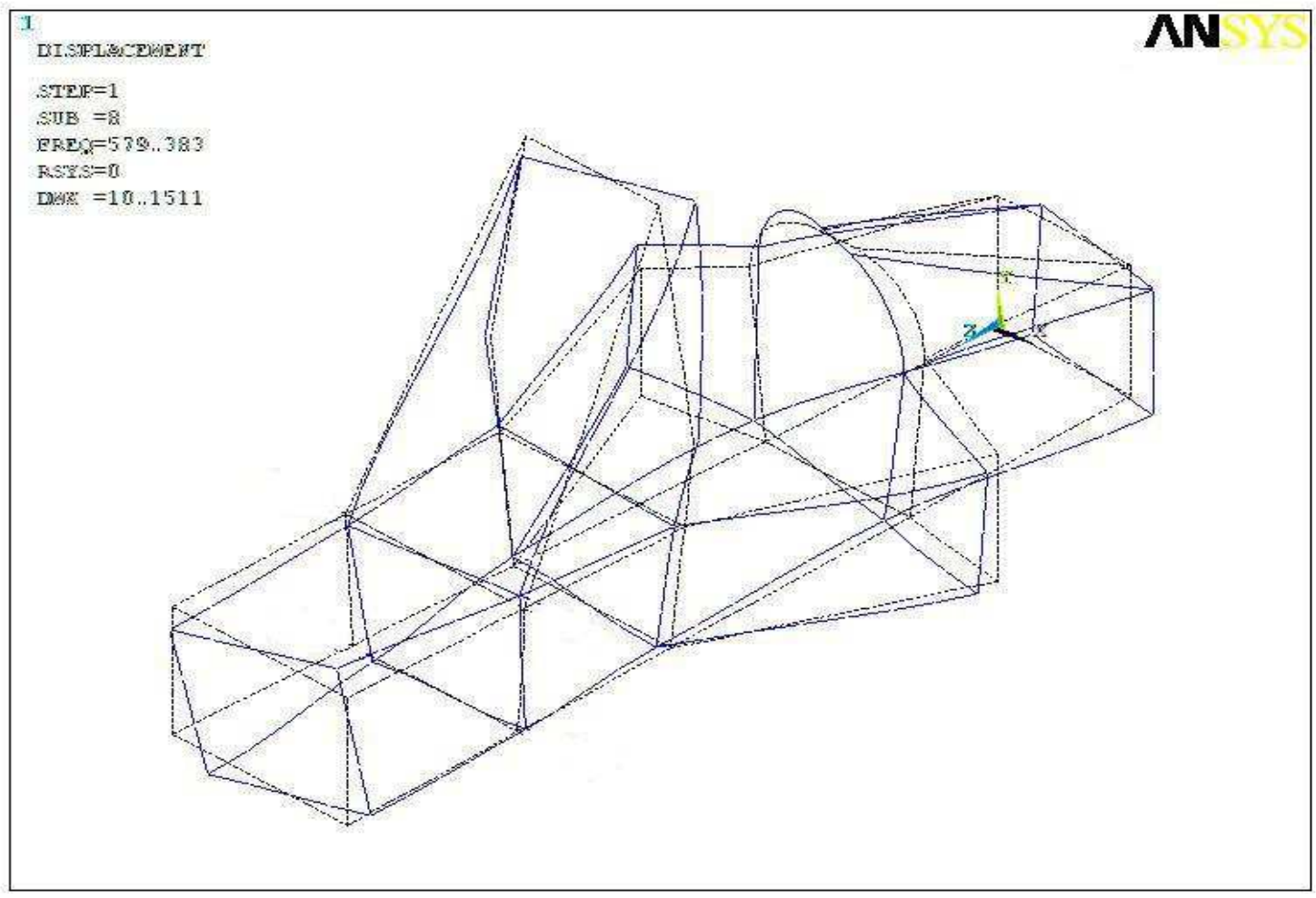

Fig. 11. Fifth mode shape

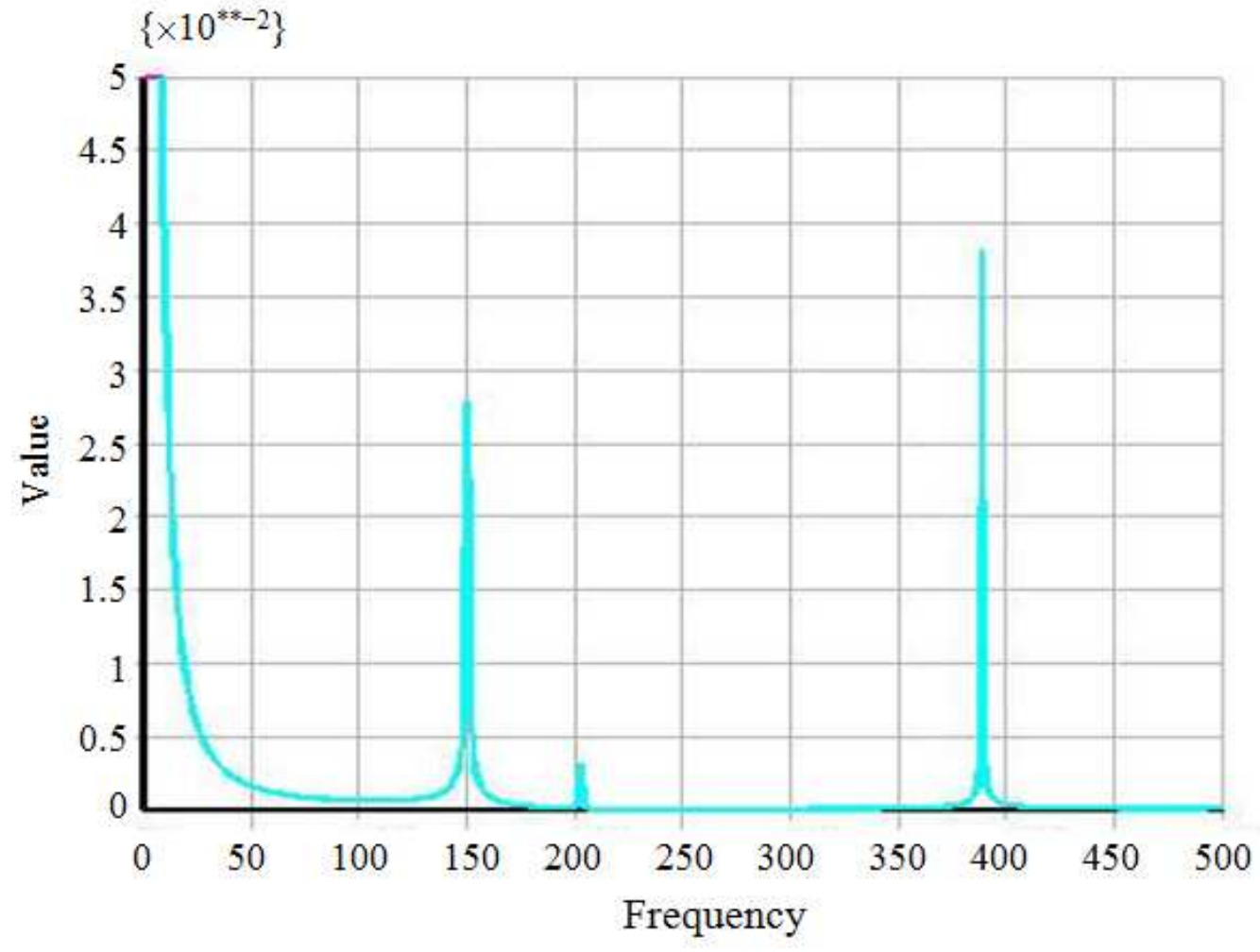

Fig. 12. Chassis structure harmonic response by $10 \mathrm{~N}$ load 
The result from ANSYS solver shows large deformation caused by the modal frequencies and can be magnified, that in so doing, any small or large deformation can be seen in the result.

\section{Harmonic Analysis}

Harmonic analysis result is used to verify the steady-state response of a linear structure, enabling researches, engineers and chassis designer to determine whether in which the chassis can withstand resonance, fatigue or other structural problems related to vibration during its operating life. Harmonic Analysis calculates the response of a structure to cyclic loads over a frequency range and plot the response on amplitude vs. frequency graph. Amplitude vs. frequency is plotted using postprocessing option in ANSYS can be used to obtain natural frequency as show in Fig. 12.

The Fig. 12 shows that the highest amplitude recorded is at approximately $389 \mathrm{~Hz}$ with amplitude of $0.375 \mathrm{~mm}$. Resonance is occurred at this frequency since it generated the highest amplitude. Frequency at the highest peak amplitude illustrated in the plot is similar with the third mode shape frequency of the car chassis. In other words, the third mode shape frequency is the resonance frequency for the chassis.

\section{Conclusion}

The analysis found that the natural frequencies extracted using Block Lanczos Method produced 5 mode shapes within $0-800 \mathrm{~Hz}$ frequency range. All mode shapes produced natural frequencies above $100 \mathrm{~Hz}$ which is safe and comfortable for human usage, which is similar result produced from the study by Ahmad and Brahmananda (2003). Apart from that, the natural frequencies generated from the analysis also do not coincide with other external source of excitation which ranging from $1-100 \mathrm{~Hz}$, the lowest natural frequency produced from the chassis is at approximately $150 \mathrm{~Hz}$, far-off from external excitation frequency.

Mode shapes generated from modal analysis shown that different frequency produced different characteristic which include torsional, bending and combination of torsional and bending. It is an important fact that if external excitation similar to that of the natural frequencies, this will consequently result in deflection in the chassis structure. The highest displacement caused by vibration in the chassis structure is $0.375 \mathrm{~mm}$ located at the side impact protection sub-frame. Improvement can be made by installing cross member frame on both side of the sub-frame, although in this study, the amount of displacement is considered small. Thus, the overall stiffness of the chassis structure is adequate to be used in racing circuits.
The key concern in designing and fabricating a space frame chassis is to avoid resonance frequency. It is known that resonance frequency could cause excessive displacement and failure. Based on the Modal and Harmonic Analysis, the resonance frequency for the chassis structure is marked on the third natural frequency of $389.10 \mathrm{~Hz}$ with recorded maximum deflection of 0.375 $\mathrm{mm}$ at this frequency. Therefore the resonance frequency can be avoided since most forced excitation occurred at lower frequency in the range of $1-100 \mathrm{~Hz}$, which indicated that the resonance frequency is out of the critical range. Overall, the results produced from both modal and harmonic analysis are an important in finding of analysing dynamic response of a space frame race car chassis structure. The findings can be used as preliminary result before it can be validated experimentally.

\section{Acknowledgement}

The researchers would like to sincerely thank the management of Sultan Azlan Shah Polytechnic and Team Formula PSAS for the financial and technical support given during the study.

\section{Author's Contributions}

Mohammad Al Bukhari Marzuki: Lead researcher, responsible for selecting the analysis method, analysing result, data interpretation and manuscript drafting and submission.

Mohammad Hadi Abd Halim: Designer, responsible for designing the chassis structure including oversees the overall chassis fabrication process and, study the concept and design.

Abdul Razak Naina Mohamed: Responsible of the overall financial aspect of the project, which include handling initial budget request paperwork, budget allocation and, materials and equipment procurement.

\section{Ethics}

This article is original and contains unpublished material. The corresponding author confirms that all of the other authors have read and approved the manuscript and no ethical issues involved.

\section{References}

Ahmad, N. and R.K. Brahmananda, 2003. Determination of fundamental natuaral frequencies of the motorcycle chassis. SASTECH J.

ANSYS, 2010. Documentation for ANSYS. SAS IP.

Ferreira, P.A. and A. Lopez-Pita, 2012. Numerical Modeling of high-speed train/track system to assess track vibrations and settlement prediction. J. Trans. Eng., 139: 330-337.

DOI: 10.1061/(ASCE)TE.1943-5436.0000482 
Wang, G. and F. Sun, 2010. Notice of retraction FEA and optimize design of a new type structure of FOG. Proceedings of the 2nd International Conference on Mechanical and Electronics Engineering, Aug. 1-3, IEEE Xplore Press, Kyoto, pp: V1-276-V1-279. DOI: 10.1109/ICMEE.2010.5558547

Gou-Lin, X. and Z. Dai-Sheng, 2008. Analysis of BIW and its shape correlation research. J. Automobile Sci. Technol., 10: 39-43.

Hai-Fei, W., J. Kun-Kun and G. Zi-peng, 2014. Random vibration analysis for the chassis frame of hydraulic truck based on ANSYS. J. Chem. Pharmaceutical Res., 6: 849-852.

He, J. and Z.F. Fu, 2001. Modal Analysis. 1st Edn., Butterworth-Heinemann. Oxford, Boston, ISBN-10: 0080511783, pp: 304.

Lin, N., Z. Hui and D. Chao, 2012. Research on RFID application mode in automotive manufacturing production line. Comput. Eng., 38: 224-226. DOI: $10.3969 /$ j.issn.1000-3428.2012.04.073

Luo, J.M., Y. Jiang and Z.H. Xing, 2012. Modal analysis of mast section of hoist based on the vibration theory. Adv. Material Res., 457: 150-155. DOI: 10.4028/www.scientific.net/AMR.457-458.150

Madhu, P.S. and T.R. Venugopal, 2014. Static analysis, design modification and modal analysis of structural chassis frame. Int. J. Eng. Res. Appli., 4: 06-10.

Mahmoodi-k, M., I. Davoodabadi, V. Visnjic and A. Afkar, 2014. Stress and dynamic analysis of optimized trailer chassis. Technical Gazette, 3: 599-608.

Naveen, L.H. and P.R. Venkatesh, 2014. Shaker based Operating Deflection Shape (ODS) testing of two wheeler chassis. Int. J. Adv. Eng. Res. Develop., $1: 1-7$.
Rao, S.S., 2004. Mechanical Vibration. 4th Edn., Pearson Education Press.

Samrudhi, R.S., K.K. Dhande, V. Singh and N.I. Jamadar, 2014. Modal and harmonic analysis in a stepped vibratory bowl feeder. Int. Eng. Res. Technol., 3: 121-130.

Suhir, E. and R. Burke, 1994. Analysis and optimization of the dynamic response of a rectangular plate to a shock load acting on its support contour with application to portable electronic packages. Proceeding of the 44th Electronic Components and Technology Conference, May 1-4, IEEE Xplore Press, Washington, pp: 1037-1049. DOI: $10.1109 /$ ECTC.1994.367500

Venugopal Rao, L.V. and P.P. Chinta, 2014. Dynamic behaviour of three-wheeler passenger vehicle using finite element method, rigid body modelling and comparison with intelligent design automation. J. Res. Sci. Technol., 2: 45-55.

Wenlin, W., S. Cheng, L. Mingjun and Z. Jun, 2010. Experimental modal test for structure refinement of an automotive chassis. Proceedings of the International Conference on Measuring Technology and Mechatronics Automation, Mar. 13-14, IEEE Xplore Press, Changsha City, pp: 174-177. DOI: 10.1109/ICMTMA.2010.39

Yang, Y., W.W. Liou, J. Sheng, D. Gorsich and S. Arepally, 2012. Shock wave impact simulation of a vehicle occupant using fluid/structure/dynamics interactions. Int. J. Impact Eng., 52: 11-22. DOI: 10.1016/j.ijimpeng.2012.09.002

Zhang, X. and Z. Kang, 2013. Topology optimization of damping layers for minimizing sound radiation of shell structures. J. Sound Vibration, 332: 2500-2519. DOI: 10.1016/j.jsv.2012.12.022 